\title{
A Study on Covid-19 from Nosocomial Perspective
}

\author{
Sahil Kapoor and Mithun Abraham \\ 'DDepartment of ENT Shree Guru Gobind Singh \\ Tricentary University,Gurugram, Haryana,India. \\ Corresponding author email: neo_mikku007@yahoo.com
}

\begin{abstract}
With the outbreak of COVID-19 in the whole world the hospitals were fully occupied with the patients infected with the disease. This epidemic is so severe that the even the doctors, other staff involved in the treatment of the disease was not spared from the infection. Even though they adopted proper measures like wearing masks, gloves or PPE to ensure to save themselves from the virus. But even then they got affected to some percentage and the infected staff became the reason for the spread of the virus further. Apart from the staff other hospital acquired infections were also responsible. The present study is also based on the collection of data for the spread of the virus through the medical staff and the other hospital acquired infections(HAIs). This study will help the medical policy makers and hospitals to look into the proper management of the situations in future, which may include measureslike making proper isolation wards, safety standards or separate passages for the epidemic patients in future.
\end{abstract}

KEYWORDS: BACTERIA,COVID-19,HELMINTH,INFECTION,MERS,NOSOCOMIAL,PATHOGENS,PROTOZOAN, SARS,TOXIN, VIRUS.

\section{INTRODUCTION}

COVID-19 stands for the Corona Virus Disease. It is an infectious disease caused by a newly spread virus in all the countries of the world. It originated from a lab situated in China. People infected with this newly spread disease experience mild to moderate fever and the respiratory related problems, phlegm, chest blockage. For their treatment special kind of treatment has to be carried out and with full care because this virus is so much dangerous that even the treatment providing doctors and nurses or any person coming in contact with such an infected person would also get infected. Those people get most affected who have weak immune system and cannot tolerate even some mild fever and suffer a lot of pain like old people, babies or young people with low immunity or those people who are already suffering from another kind of immunity decreasing diseases

Biosc Biotech Res Comm P-ISSN: 0974-6455 E-ISSN: 2321-4007
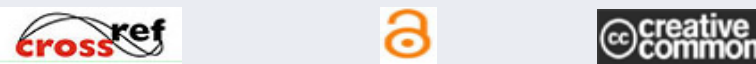

Identifiers and Pagination

Article Information

Year: 2021 Vol: 14 No (7) Special Issue

Received: 14 $4^{\text {th }}$ May 2021

Pages: 268-272 Accepted after revision: $18^{\text {th }}$ July 2021

This is an open access article under Creative

Commons License Attribn 4.0 Intl (CC-BY).

DOI: $h t t p: / / d x . d o i . o r g / 10.21786 / b b r c / 14.7 .59$ like heart or cardiovascular disease, respiratory problems like asthma, diabetes or sugar, cancer, AIDS like diseases.

The best prevention methodology from such a dangerous disease is to be well aware about the causes of spread of this disease. Prevention techniques are best to adopt for this disease than to go for the treatment. For that keep washing the hands after some time and whenever coming to home from outside tour and use of alcohol can be made for instant cleaning and making the hands germ free and avoid touching the face. It spreads mainly through the saliva or the discharge coming from the nose whenever an infected person either coughs or he/she sneezes. So adopting the respiratory etiquettes will help a lot like coughing into the angles or bent elbow.

Now the medical institutions or hospitals providing treatment for such a dangerous virus disease are no less than a potential source of infection because disease not only spread through the direct contact with the infected person but also through the indirect contacts like exposure to infected doctors, nurses or the medical staff. As these persons come in direct contact with the infected person for his/her treatment they also get infected even after a lot of safety precautions. Now when such infected virus carriers go for other places and touch any of the objects or come in contact with the persons either 
in the hospital or at home the chance of their get infected also increases very much.

When such an object is touched by another non infected person then that person also gets infected and thus a long chain gets initiated which keep on elongating. So, it is very much essential to treat such persons with utmost care and with full on safety standards and in isolation wards and the doctors or any person of the medical staff should be sanitized properly before leaving his work place or after operating on the infected persons.

A nosocomial infection is acquired due to an infection or toxin already present in a certain location like in a hospital where infected individuals are admitted. Nosocomial infection term is interchangeably used with the terms health-care associated infections and hospital acquired infections which in short are written as HAI's. For a HAI, the infection must not be present before someone has been under medical care. Rate of occurrence of the HAI's is 2-3 folds higher in developing countries as compared to the developed countries like USA, Europe.

Most commonly area where HAI's can occur is Intensive Care Units(ICU's), where the serious disease cases are treated by the doctors(K. Naidu et. al. (2014)). At least $10 \%$ persons got infected with the HAI's which may further go up-to $50 \%$ in critical cases that depends upon the crude mortality, hospital costs and length of stay in ICU(P. Eggimann et. al. (2001)). As the medical care system becomes more and more complex and antibiotic resistance increases, the cases of HAI's keep on increasing, but HAI's can be prevented in a lot of healthcare situations.

HAI's are caused by a wide range of pathogens, ventilatorassociated pneumonia and central line infections. It has been seen that such diseases arise after $48 \mathrm{~h}$ of hospitalization. Such diseases are opportunistic and micro-organisms of low virulence can also infect those patients easily whose immune system is weak(H. Mythri et. al. (2014)). HAI's are more importantly arising from exogenous sources that may be any part of the hospital environment like people, objects, food, water and air present in the hospital leading to exposure of bacteria, pathogens or anything which can cause infection.

To prevent such diseases, management of the hospitals has to spend great sum of money in ensuring prevention of pathogen exposure. The most prevalent nosocomial infections in ICU are urinary tract infections (UTI), pneumonia, bloodstream infections, skin and soft tissue infections, gastroenteritis, hepatitis and central nervous system infections like meningitis. The infections are caused by the pathogens which are also known as germs that cause diseases that may be bacteria, virus, fungus, protozoan, and helminth. These can further be classified as mentioned below:

Bacterial infections: Bacteria is a single cell micro-organism. It has no definite shape and size. Thus they exist in diverse category. Bacteria can be found in every environment like water bodies, soil and in the human body too(Healthline et. al.). Some can exist at extreme temperature or even can expose to the radiations. Even though there are many bacteria in and on our body, these often don't cause the disease and some bacteria in our digestive system or tract helps to digest out food. But some bacteria can be the reason for the infections and some bacterial infections are shown in Table 1:

Table 1. Bacterial infections caused by nosocomial origin.

\begin{tabular}{|c|c|c|c|}
\hline \multirow{8}{*}{ Bacterial Infections } & Strep Throat & \multirow{2}{*}{$\begin{array}{l}\begin{array}{l}\text { Clostridium } \\
\text { difficile }\end{array} \\
\text { Tuberculosis }\end{array}$} & \multirow{2}{*}{$\begin{array}{l}\text { Tetanus } \\
\text { Anthrax }\end{array}$} \\
\hline & \begin{tabular}{|l|} 
Urinary throat \\
infection(UTIs)
\end{tabular} & & \\
\hline & $\begin{array}{|lr|}\text { Food } & \text { Poisoning } \\
\text { bacteria } & \text { E.coli, } \\
\text { Salmonella } & \text { or } \\
\text { Shigella } & \\
\end{array}$ & Whooping cough & \\
\hline & $\begin{array}{l}\text { Cellulitis such as } \\
\text { Staphylococcus } \\
\text { aureus }\end{array}$ & \begin{tabular}{|l|}
$\begin{array}{l}\text { Pneumococcal } \\
\text { pneumonia }\end{array}$
\end{tabular} & \\
\hline & Vaginosis & \begin{tabular}{|l|} 
Bacterial \\
meningitis
\end{tabular} & \\
\hline & \begin{tabular}{|l|} 
Gonorrhea \\
\end{tabular} & Lyme disease & \\
\hline & Chlamydia & Cholera & \\
\hline & \begin{tabular}{|l} 
syphilis \\
\end{tabular} & \begin{tabular}{|l|} 
botulism \\
\end{tabular} & \\
\hline
\end{tabular}

These infections are treated with antibiotics which either impede the bacterial growth from their multiplication or kill them outright(A. Rosca et. al. (2018)). There are different classes of antibiotics and prescription of antibiotics depends upon the type of bacterium causing the infection.Fungus is another type of broad group of organisms that includes the yeasts and molds. All of these are available or can be found in the environment, even in the soil, in the moist places like bathrooms or any wet place and even on or in our bodies. In certain cases, fungi are so small that they cannot be seen with the naked eye. In other times, these can be seen on the tiles of the bathrooms like mold. Fungal infections are shown in Table 2.

Table 2. Fungal infections caused by nosocomial origin.

\begin{tabular}{|l|c|c|}
\hline \multirow{4}{*}{ Fungal Infections } & vaginal yeast infections & athlete's foot \\
\cline { 2 - 3 } & fungal meningitis & ringworm \\
\cline { 2 - 3 } & Cryptococcus infection & \\
\hline & histoplasmosis & \\
\hline & aspergillosis & \\
\hline & thrush & \\
\hline & & \\
\hline
\end{tabular}

Such infections can be treated with the antifungal medicines or the ointments. The prescription of the ointment depends upon the type of the fungal infection a person is infected with. For example, ointment or cream can be prescribed for the infections like ringworm or on foot of a person.Oral medicines are also available which serve the purpose of antifungal agents. For the severe infections inside the body intravenous medicines can be used for the fungal treatment. The present study provides a new perspective towards the pandemic COVID-19 as a new form of nosocomial infection. 
Literature Review: B. Carter etal. in their research paper studied that due to COVID-19 there was reductionin number of non COVID-19 casesbecause of the fear of the acquiring of the infection of COVID-19 so they carried out a study on the nosocomial infections due to COVID-19. In their study they studied time for all causes on infection, for the seventh day and time to discharge(B. Carter et. al.
(2020)). They found that NC acquired infection had low rate of mortality, for the seventh day there was no change in the rate of mortality. They also studied that $\mathrm{NC}$ acquired persons took longer time to die than the infected persons. On the average $\mathrm{NC}$ acquired took 14 days to survive while the infected took 10 days to die.Jie Ren et Al., in their study found the healthcare workers who were mostly affected with the COVID-19 infections.

Table 3. Questions involved in the survey according to mentioned questionnaire groups.

\begin{tabular}{|c|c|}
\hline Unique Health care worker ID & \\
\hline 2019-nCOV patient ID & \\
\hline Patient ID came for check-up & \\
\hline 1. Current Status & Alive/Dead \\
\hline 2. Contact Identifier Information & \\
\hline First name & \\
\hline Surname & \\
\hline Sex & Male/female/others \\
\hline DOB & \\
\hline Contact number & \\
\hline Age & $0-10 / 11-20 / 21-30 / 30-40 / 40-50 / 50+$ \\
\hline Email & \\
\hline National social number/Identifier & \\
\hline Country of residence & \\
\hline Nationality & Indian/NRI \\
\hline Ethnicity & \\
\hline Smoker & Yes/No \\
\hline Occupation in health care facility & \\
\hline Department visited by patient & \\
\hline $\begin{array}{l}\text { 3. Do you came in contact with the } \\
\text { COVID-19 Positive patient }\end{array}$ & Yes/No \\
\hline For how much time do you came in contact & $\mathrm{H} \_\mathrm{M}$ \\
\hline $\begin{array}{l}\text { Did you wear your mask while meeting the } \\
\text { patient? }\end{array}$ & Yes/No \\
\hline $\begin{array}{l}\text { Did you sanitize your hands and wash your } \\
\text { hands with soap? }\end{array}$ & Yes/No \\
\hline Did you wear PPE & Yes/No \\
\hline Are you suffering from any other disease? & Yes......... No \\
\hline $\begin{array}{l}\text { 4. Do you feel any Symptoms of } \\
\text { COVID-19 }\end{array}$ & Yes/No/Not sure \\
\hline Date of experiencing the first symptom & $\mathrm{dd} / \mathrm{mm} / \mathrm{yyyy}$ \\
\hline Do you have any of following symptoms? & Yes/No \\
\hline Sore Throat & Normal/Mild/Severe \\
\hline Fever & $\ldots \ldots{ }^{\circ} \mathrm{C}$ \\
\hline Headache & Yes/No \\
\hline Respiration Problem & Mild/Severe/Normal \\
\hline
\end{tabular}

Table 4. Shows Medical staff and other HAIs percentage infected with COVID-19, SARS, and MERS. COVID19, SARS (Severe Acute Respiratory Syndrome), MERS (Middle East Respiratory Syndrome)

\begin{tabular}{|l|l|l|l|}
\hline & COVID-19 & SARS & MERS \\
\hline Medical Staff & $33 \%$ & $37 \%$ & $19 \%$ \\
\hline Other HAIs & $2 \%$ & $24 \%$ & $36 \%$ \\
\hline
\end{tabular}

They found that the frontline healthcare workers providing services in neck, throat, ear were affected mostly(J.Ren et. al. (2020)). So a number of measures were adopted to stop the spread of this epidemic and the situation came under the control. Qi Zhou et al., in their research proposed the data based on the 40 studies. In their studies they found that out of the confirmed cases of COVID-19, SARS and MERS the mostly affected were the doctors and medical staff which included nurses and other members of the medical staffbecause they were in direct contact with the infected persons(Q. Zhou et. al. (2020)). The present study identifies prevalence of nosocomial COVID-19 infections and other normal COVID-19 infections. 


\section{MATERIAL AND METHODS}

Data Collection and Analysis: The responses were majorly based on selection of multiple choices or single line reasoning input. The response input was provided for each of the question mentioned in the Table 3 . The data collection was done with inclusion criteria of involving nondiabetic individuals of all age groups. The data analysis was performed by OriginPro software with one-way ANOVA for evaluating statistical significance(B. L. Brown et. al. (1982)).

\section{RESULTS}

A number of studies were conducted to find the Nosocomial origin of the COVID-19. The first study included in total 1564 patients from 10 hospitals of each India, US and Italyand the collected outcomes on patients were admitted up-to August 28th, 2020. Out of the total cases in total 1/8th cases of COVID-19 infections were NC and 321 patients out of them died(B. Carter et. al. (2020)). The survival time of the $\mathrm{NC}$ patients was more than the community acquired COVID-19(CAC) because CAC patients died in 7 days while the NC patients died in 12 days.

It was concluded in the primary analysis that $\mathrm{NC}$ infection was associated with a lower mortality rate while the secondary analysis has no difference in 7-days interval in mortality.It was also noticed that the $\mathrm{NC}$ patients required longer period in recovery.

From the second study which further included 80 studies it was seen that among the confirmed patients, the NC with early outbreaks of COVID-19, SARS and MERS were $44 \%, 36 \%$ and $56 \%$ resp. Out of the confirmed patients; the medical staff and the NC(HAIs) accounted infections have been shown in Table 4.

Figure 1: Nosocomial Disease Infection Cases Percentage. COVID-19,SARS (SevereAcute Respiratory Syndrome), MERS (Middle East Respiratory Syndrome)

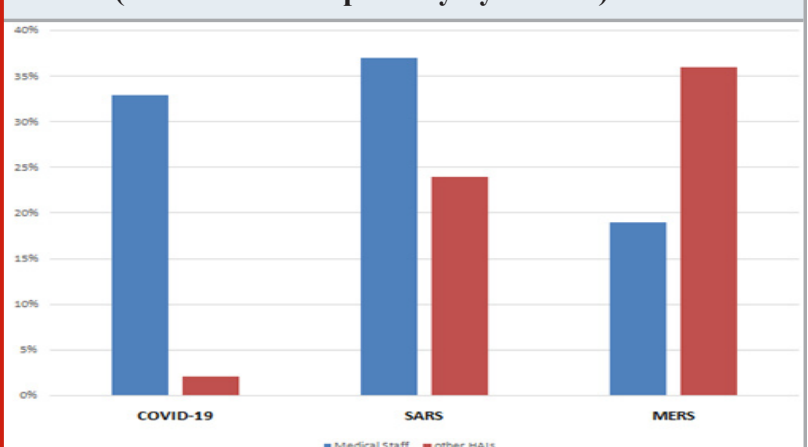

Out of the above shown percentage, the most effected were the nurses and the doctors among the medical staff because the nurses and the doctors come in direct contact with the patient for their treatment. It is not possible to treat a patient without touching the patient like for operating a surgery, operation on a person already infected with any of the above diseases. Even though the doctors and nurses use PPE for the best safety procedures, changing those clothes or little bit opening of such PPE can cause pathogen exposure to health care providers. Further such doctors and nurses also came in contact with other patients or persons, those persons may also get infected as the pathogen can be persisting even on PPE on its outside surface.

\section{CONCLUSION}

From the above study it is found that some percentage of COVID-19 cases was the result of nosocomial transmissions. Even though no case of COVID-19 comes without risk and patients with $\mathrm{NC}$ infection had no greater risk of mortality and are carry less risk than the people admitted to hospital with COVID-19(B. Chang et. al. (2015)). People who got affected form the nosocomial infections include both the hospital staff and the patients visiting the hospital either for treatment or accompanying a patient. Therefore, the patients visiting the hospital should always pay attention on their personal protection.

At the same time, medical institutions can reduce the spread of the virus through triage, setting up isolation wards, separate fever check-up clinics(D. R. Jenkins et. al. (2017)). Even the passages for the epidemic or communicable diseases should be made separate. Awareness of the disease needs to be improved among the medical staff, so that they can protect themselves adequately. Some other required measures can also be taken to stop the spread of the virus within the hospitals.

\section{REFERENCES}

Aglio, L.S., Lekowski, R.W. and Urman, R.D. eds., 2015. Essential Clinical Anesthesia Review: Keywords, Questions and Answers for the Boards.

Carter, B., Collins, J.T., Barlow-Pay, F., Rickard, F., Bruce, E., Verduri, A., Quinn, T.J., Mitchell, E., Price, A., VilchesMoraga, A. and Stechman, M.J., 2020. Nosocomial COVID-19 infection: examining the risk of mortality. The COPE-Nosocomial Study (COVID in Older PEople). Journal of Hospital Infection, 106(2), pp.376-384.

Dayanand, M. and Rao, S.K.M., 2004. Prevention of hospital acquired infections: a practical guide. Medical Journal, Armed Forces India, 60(3), p.312.

Eggimann, P. and Pittet, D., 2001. Infection control in the ICU. Chest, 120(6), pp.2059-2093.

Ezhilarasi, G.D., Latchoumi, T.P. and Balamurugan, K., 2020. UIP_A Smart Web Application to Manage Network Environments, Advances in Intelligent systems and computing book series.

Jenkins, D.R., 2017. Nosocomial infections and infection control. Medicine, 45(10), pp.629-633.

Mythri, H. and Kashinath, K.R., 2014. Nosocomial infections in patients admitted in intensive care unit of a tertiary health center, India. Annals of medical and health sciences research, 4(5), pp.738-741.

Mishra, P., Jimmy, L., Ogunmola, G.A., Phu, T.V., Jayanthiladevi, A. and Latchoumi, T.P., 2020, December. Hydroponics cultivation using real time iot measurement system. In Journal of Physics: Conference Series (Vol. 1712, No. 1, p. 012040). IOP Publishing. 
Naidu, K., Nabose, I., Ram, S., Viney, K., Graham, S.M. and Bissell, K., 2014. A descriptive study of nosocomial infections in an adult intensive care unit in Fiji: 2011-12. Journal of tropical medicine, 2014.

Prasath, S. (2020). Probabilistic Mceliece Public-Key Cryptography Based Identity Authentication For Secured Communication In Vanet. Solid State Technology, 63(6), 10167-10182.

Prasath, S. Validating Data Integrity in Steganographed Images using Embedded Checksum Technique. International Journal of Computer Applications, 975, 8887.

Ren, J., Yang, X., Xu, Z., Lei, W., Yang, K., Kong, Y., Qu, J., Liao, H., He, Y., Chen, H. and Wang, Y., 2020. Prevention of nosocomial COVID-19 infections in otorhinolaryngology-head and neck surgery. World Journal of Otorhinolaryngology-Head and Neck Surgery, 6, pp.S6S10.
Rosca, A. and Cerca, N., 2018. Bacterial vaginosis. Diagnostics to Pathogenomics of Sexually Transmitted Infections, p.257.

Venkata Pavan, M., Karnan, B. and Latchoumi, T.P., 2021. PLA-Cu reinforced composite filament: Preparation and flexural property printed at different machining conditions. Advanced Composite Materials, https://doi. org/10.1080/09243046.2021, 1918608.

Williams, R.N., Taylor, C.B. and Hintze, W.J., 1989. The influence of religious orientation on belief in science, religion, and the paranormal. Journal of Psychology and Theology, 17(4), pp.350-356.

Zhou, Q., Gao, Y., Wang, X., Liu, R., Du, P., Wang, X., Zhang, X., Lu, S., Wang, Z., Shi, Q. and Li, W., on behalf of COVID-19 Evidence and Recommendations Working Group.(2020). Nosocomial infections among patients with COVID-19, SARS and MERS: a rapid review and metaanalysis. Annals of Translational Medicine, 8, p.629. 